\title{
THE NUCLEAR ROCKET:
}

NEW POWERPLANT

FOR

SPACE VEHICLE

PROPULSION

\author{
Lt. Col. Howard R. Schmidt, USAF \\ and \\ Major Ralph S. Decker, USAF
}

March 1960

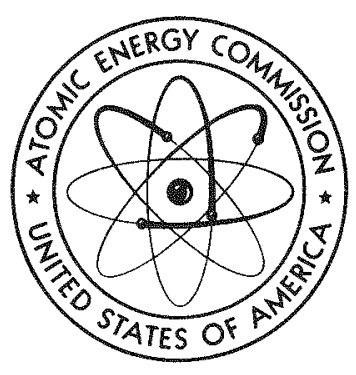

Nuclear Rocket Section

Division of Reactor Development

United States Atomic Energy Commission 


\section{DISCLAIMER}

This report was prepared as an account of work sponsored by an agency of the United States Government. Neither the United States Government nor any agency Thereof, nor any of their employees, makes any warranty, express or implied, or assumes any legal liability or responsibility for the accuracy, completeness, or usefulness of any information, apparatus, product, or process disclosed, or represents that its use would not infringe privately owned rights. Reference herein to any specific commercial product, process, or service by trade name, trademark, manufacturer, or otherwise does not necessarily constitute or imply its endorsement, recommendation, or favoring by the United States Government or any agency thereof. The views and opinions of authors expressed herein do not necessarily state or reflect those of the United States Government or any agency thereof. 


\section{DISCLAIMER}

Portions of this document may be illegible in electronic image products. Images are produced from the best available original document. 


\section{LEGAL NOTICE}

This report was prepared 28 an account of Government sponsored work. Nelther the United States, nor the Commission, nor any person acting on behalf of the Commisaton:

A. Makes any warranty or representation, expressed or implied, with respect to the accuracy, completeness, or usefulness of the information contalned in this report, or that the use of any information, apparatus, method, or process dieclosed in this report may not infringe privately owned rights; or

B. Assumes any liabilities with respect to the use of, or for damages resulting from the use of any information, apparatus, method, or process disclosed in this report.

As used in the above, "person acting on behalf of the Commision" Includes any employee or contractor of the Commisaton, or employee of auch contractor, to the extent that auch employee or contractor of the Commission, or employee of such contractor prepares, disseminates, or provides access to, any information pursuant to his employment or contract with the Commission, or his employment with such contractor.

Printed in USA. Price $\$ 0.50$. Avallable from the Office of Technical Services, Department of Commerce, Washington 25, D. C.

Tregared for presentation at the American Power Conference sponsored by the Illinuis Institute of Technole of Chacago, Introis Mareh 29,4000 


\section{INTRODUCTION}

Power developments for the transport of men and machines above the surface of the earth are intriguing, challenging, and constitute a rapidly advancing segment of our power industry. High specific power and performance is the key to progress for aerospace travel, and the requirements have been increasing by order of magnitude increments. This increasing demand, spurred by defense urgency, has required the development of a series of basic powerplants, each capable of greater power production along with higher specific powers. The industry has demonstrated an ability to meet each new challenge, and has strongly contributed to our position of air supremacy. The development of new powerplant types is necessary for operations in space. The introduction and acceptance of nuclear power is essential to meet space power demands and the attainment of supremacy in space.

During the past 15 years, the internal combustion engine was developed to its peak of military usefulness. Following the introduction of the aircraft gas turbine by the British, its further development growth in the United States followed a logical pattern, and its development cycle for military purposes has been essentially completed. The Germans introduced the chemical rocket and successfully applied it to ballistic missiles. That early achievement stemmed from the published experiments of an American scientist, Dr. Robert H. Goddard. The Russians contimed the development of large chemical rockets while a major portion 
of our effort was diverted to small engines for other applications. The decision to seriously pursue the development of the intercontinental ballistic missile resulted in rapid developmental growth of the chemical rocket in the past five years. The outstanding capability of our power industry was again demonstrated, once given a clear requirement on which to proceed. This brief look at the past is extremely pertinent to current discussions concerning our nation's lag in rocket power and the establishment of national goals for technological accomplishment.

The decision to initiate a new powerplant development is not a straight forward technical matter. It involves a complex combination of political, economical, and human factors as well as technical judgment. Each powerplant has its proponents who often tend to underestimate the potential of a new type, or for a variety of reasons are reluctant to change. The question of timing is obviously important. It is not generally known, for example, that the Air Force considered a muclear rocket development program in 1946 for which some research was accomplished. In this instance, the timing was premature in view of the scarcity of fissionable material and the application was not sufficiently clear.

In the development cycle of any powerplant a period of performance optimization is reached where limited performance gains can only be achieved by added complexity and strikingly higher unit cost. Today the chemical rocket engine is entering this period of performance optimization. Developments likely to establish the upper limit of thrust which can be 
oractically achieved with a single thrust chamber are underway. Propellant combinations which appear to be capable of providing about the maximum energy obtainable from the chemical bond are being introduced into development engines. Thrust chambers are being clustered in large numbers, and the physical size of the assembled engine is such that it must be moved to launch areas by water barge rather than road or rail, and new bridges are required for even a short journey by road. There are ways around the practical problems -- for a price -- but the trend must be recognized and serious consideration given to the development of the next generation of powerplants for aerospace propulsion.

Having looked briefly at the rapidly changing technology in aerospace propulsion during the past 15 years, let us look ahead a similar period of time and examine a single potential powerplant for space application -- the nuclear rocket. By way of introduction of this subject to the American Power Conference, this paper is an attempt to survey in a fundamental and practical way many of the aspects of nuclear rocket propulsion pertinent to early space vehicle application. The muclear rocket is discussed in terms of its basic cycle, technical program status, and its possible performance advantage over its currently popular contemporary. A practical approach is suggested for early integration into planned space vehicles. 
The nuclear rocket involves a direct combination of the principles of rocketry and nuclear reactor technology. Rocket engines, whether nuclear or chemical, are distinguished from other jet propulsion devices primarily by the fact that the working fluid or propellant is carried aboard the vehicle being propelled. Therefore the duration of operation is limited by the mass of propellant carried. This places a tremendous premium on the power produced per pound of propellant consumed. Like all jet propulsion devices, rocket engines produce thrust through the heating of a working fluid to high temperature and expelling it at high velocity through a nozzle. In all chemical rockets, the propellants themselves provide the energy source and are raised in temperature by the heat of combustion. The exhaust jet velocity is proportional to the square root of the absolute temperature at the nozzle inlet, and varies as the impulse imparted to a given mass of propellant. Exhaust jet velocity then, or its equivalent, specific impulse, is the primary index of rocket engine efficiency and vehicle performance. Specific impulse is popularly defined as the propellant flow rate required to produce a pound of thrust. There is one simple expression for specific impulse which clearly illustrates the basic difference between chemical and nuclear rockets as well as the fundamental limitations of the former. For both

$$
\operatorname{I\alpha } \sqrt{\frac{E}{\bar{M}}}
$$

chemical and nuclear rockets, specific impulse, I, varies directly as the 
square root of the energy, $E$, and inversely as the square root of the mean molecular weight, $\bar{M}$, of the propellant exhaust products. The energy released by the heat of combustion and molecular weight are inherent properties of the chemical propellant combination. The best high energy chemical propellants have molecular weights in the range of 15 to 20 . Since the energy is generated independently by the fission process in the nuclear rocket, a propellant of the lowest possible molecular weight, such as hydrogen, can be selected. For an equivalent energy release to the propellant in both systems, the use of hydrogen will provide a factor of three increase in specific impulse for the muclear rocket. The energy per unit mass from fissile fuel is about $10^{7}$ times that available from the best chemical propellants; however, we are presently unable to convert that energy efficiently in a reactor. It is the choice of hydrogen which gives the muclear rocket its advantage at this time.

\section{Powerplant Cycle and Operation}

The functional operation of a molear rocket engine and the design of many of its components is strikingly similar to that of its chemical counterpart. The primary element of change is the substitution of a nuclear reactor for the combustion chamber in the conventional system. In both engines, this component is the heart of the system and embodies most of the development problems and fundamental performance limitations. These engine systems are illustrated schematically in Figure I, using an 
advanced hydrogen-oxygen chemical system for comparison with the nuclear system. In the nuclear system hydrogen is stored in a tank, pumped to high pressure, passed through a flow control system to the reactor where it is heated to high temperature by the fuel elements, and is discharged through a regeneratively-cooled nozzle. In general, the chemical rocket requires a fuel and an oxidizer. These propellants are stored in tanks, separately oumped to high pressure, passed through a flow control system, then are atomized by injector orifices, mixed, ignited, burned in a combustion chamber, and discharged through a regeneratively-cooled nozzle. The number of tanks, pumps, lines, and valves required in the bi-propellant chemical system are double those needed in the monopropellant nuclear system. The problems of propellant injection, mixing, ignition, and combustion which have long plagued chemical rocket development are non-existant in the nuclear system. These processes and mechanisms have adversely affected operational reliability in missiles and space vehicles. The production of heat from fission is positive and independent of the space environment. Heat release and propellant flow rate can be independently controlled. This permits a wider range of thrust variation at constant temperature and specific impulse. Hence, a reactor permits an additional degree of freedom in engine control which is an imoortant advantage for space vehicle operations. The engine control system is, however, far more complex than that required for the chemical rocket. The similarities in the two systems permit the direct application of chemical rocket technology to nuclear rocket development and implies for the latter that primary emphasis be placed on the reactor. 


\section{General Reactor Considerations}

High specific power or high power density, kw/Ib., peak operating temperature, and fast startup are primary reactor design objectives. The nuclear rocket conceot requires that the energy released by the fission process be transferred to the propellant at the highest possible efficiency. Core designs in which $\mathrm{U}^{235}$ is contained in the solid, liquid, and gaseous state have all been considered. ${ }^{1,2}$ of these possibilities, only the solid-fuel-element-heat-exchanger reactor shows promise for early use in nuclear rockets. Hence, the temperature to which the propellant can be heated is necessarily below the melting point of fuel element materials. The prospects look favorable when one considers that hydrogen heated to only 400 degrees $C$. provides a specific impulse of 475 , that which characterizes advanced chemical rockets using hydrogen-oxygen. The fuel element base materials of interest are the ceramics, including the refractory metal carbides, and the refractory metals, which have melting points extending to about 4,000 degrees C. The melting points of these materials in combination with uranium or a uranium-bearing compound are somewhat lower. The addition or presence of a moderator material also tends to limit operating temperatures. It is generally believed that a specific impulse of 800 which requires a temperature of about 2,000 degrees $C$. can be achieved in a first generation rocket reactor. $1,3,4,6$ Further growth to a specific impulse of 1200 as an upper limit, including dissociation effects, may be possible. The range of power densities that might be achieved is 
$100-600 \mathrm{kw} / \mathrm{Ib}$. Achieving such performance might appear hopeless in terms of current power reactor practice unless one considers that an operating life of from 5 to 30 minutes is the range of interest for the nuclear rocket. Nevertheless, the engineering problems of incorporating uranium into these materials, and fabricating them into shapes for most efficient heat exchanger design, are formidable. The development of fuel element materials with high temperature strength, thermal shock resistance, and propellant corrosion resistance is the heart of the reactor problem.

An examination of the neutronic properties of possible high temperature materials, the range of reactor powers of interest, and the requirement for high power density suggests that both thermal and fast reactors be considered. The terms "thermal" and "fast" are relative and each implies a range of neutron energies in which the predominant number of fissions occur. A fast reactor has no moderator to slow neutrons down, so fission is caused by fast neutrons. Because of the relatively low fast-fission cross section, higher uranium loading of the fuel element material is required to obtain a critical mass. Some of the higher melting point materials such as hafnium carbide, tantalum carbide, and tungsten have high neutron absorption resonances above the thermal range. The use of these materials in a fast reactor is one of the means possible for circumventing the neutron capture problem. Most of the materials in this category have isotopes suitable for thermal reactors, but the economics of separation are not likely to be justified. 
A fast reactor is theoretically capable of a higher power density because volume and wreight are not occupied by moderator material. ${ }^{3}$ The weight saving is not in moderator alone, but in reflector and pressure shell which surround most of the core. The absence of moderator should permit slightly higher peak temperatures. The thermal reactor can also achieve very high temberatures using refractory materials with good neutronic properties such as graphite, beryllium oxide, zirconium carbide, and niobium carbide. Its greater core volume can orovide more heat transfer area, permitting growth in power without corresponding growth in weight.

A general relationshio between power and/or thrust and engine weight using fast and thermal reactor nuclear rockets and chemical rockets is shown in Figure 2. Of particular significance is the minimum critical weight of the nuclear engines at zero thrust. While engines using fast reactors are considerably lighter than thermal systems at low Dower, this advantage reverses at some power within the region of interest. The thermal reactor engine would provide both weight and economic advantages at high powers. (The chemical engine is, of course, always Iighter than the nuclear engine.) A great deal more is known today about thermal reactors. For this reason, their practical development for muclear rockets may well precede the development of fast reactors.

The unique reactor design objectives pose special problems for the reactor designer. He is faced with continual iteration of neutronic, structural, and heat transfer considerations in order to optimize each. 
These detailed design problems are described in an excellent treatment by Durham. 5

The customary slow reactor startup would be disastrous for muclear rockets since large amounts of propellant would be ejected at degraded temperatures. Hydrogen is an effective moderator and its presence in the core, even in the gaseous state, provides a significant reactivity contribution. As a coolant and moderator, its presence provides control stability at intermediate and high power operation. On startup, however, mixed phase flow entering the core could cause disastrous reactivity changes in the core. For this reason, reactor control must be carefully integrated with propellant feed system and flow controls. An integrated automatic control system design has been proposed by Helgeson. 6

\section{Propellant Considerations}

Liquid hydrogen is far from the ideal in any consideration of propellant characteristics. Its highly cryogenic character poses unique hardware development and engine control problems. With a boiling point of -217 degrees $C$. and a critical temperature of -204 degrees $C .$, storability in space, where it is subjected to high radiant heat loads is Iimited. Nevertheless, this choice has one very significant virtue for early development progress. Propellant selection during the history of chemical rocket engine development has involved a tortuous series of disagreements, evaluations, and changing objectives. Of the hundred or so possible combinations, most have been tried. Hardware design is 
dependent to one degree or another on the physical and transport properties of each fluid. The permutations and combinations of injector, ignitor, and thrust chamber designs for those propellant combinations studied have consumed millions of development dollars, years of time, and resulted in countless volumes of technical data scattered throughout the literature. It is indeed comforting to realize that nuclear rocket development will involve a single propellant, even if it is not an ideal one.

There is a performance bonus possible from hydrogen at very high temperatures where atomic hydrogen is formed by dissociation, and additional energy is released on recombination during expansion in the jet nozzle. Fortunately, this process is pressure dependent, with increasing gains available at lower pressures. This suggests that throttling a nuclear rocket for fine adjustment of vehicle velocity can be done with improved propellant consumption - if the corresponding temperature to achieve some dissociation can be obtained.

The hydrogen-oxygen propellant combination has finally been selected for upper stage chemical engines in planned space vehicles; an extremely wise selection as will be shown later. With the combined resources from both nuclear and chemical developments being applied to common hardware problems, the future outlook for successful utilization of liquid hydrogen is encouraging, if not assured. 


\section{Radiation Effects}

Nuclear rocket engine testing involves the problems associated with nuclear radiation in the form of leakage neutrons and gamma rays. Induced radiation and fission products wich escape from the fuel elements persist after shutiown denying access for maintenance and repair. This tends to limit frequency of testing and implies a development philosophy which places heavy emphasis on component, cold flow, and low power testing.

Neutron and gamma leakage adds new problems to space vehicle design. Structure and components located near the reactor will be subjected to radiation intensities several orders of magnitude higher than normally encountered in power reactor practice. Due to short exposure times, however, integrated dose is with in tolerance levels for many engineering materials. High dose rate is not a cause for concern in most materials although certain special materials may be adversely effected.

In addition to radiation damage, the absorption of radiation in solid materials close to the reactor will cause a temperature rise in the order of $10^{\circ} \mathrm{F}$. per second unless shielding or cooling is provided. Pump cavitation and unsteady flow can also occur unless precuations are taken to prevent propellant boiling. The problem of storing propellant during long periods of coasting flight is aggravated by the addition of reactor afterheat to solar heat loads. In all cases, radiation heating can be minimized or avoided although some added 
complexity and weight may be unavoidable. Spacing between reactor and critical components, provisions for auxilliary cooling and shielding are some of the options available to the designer.

Air scattered radiation and fission product release do not present problems when nuclear rockets are used in upper stages of space vehicles. While the radiation contribution to the atmosphere from ground launched nuclear vehicles would be insignificant, the shielding required for protection of astronauts from scattered radiation tends to add further complexity and weight.

Detailed radiation influences on materials, personnel, and test operations are comprehensively treated by Graves? 


\section{PROJECT ROVER}

In 1955 the Atomic Energy Commission began a program of study, research, and development to investigate the feasibility of nuclear rocket propulsion. Initiated at the request of the Department of Defense and conducted as a joint AEC-Air Force program, it is now jointly sponsored by the AEC and the National Aeronautics and Space Administration. The many research and development activities involved are known collectively as "Project Rover."

The immediate objective of the Rover program is the demonstration of feasibility of nuclear rocket propulsion through ground operation of an experimental nuclear rocket engine. This program phase is conducted under the management of the Atomic Energy Commission with technical direction centered at the Los Alamos Scientific Laboratory. The NASA provides direct program support by sponsoring the development of certain non-nuclear components required for operation of experimental reactors. Specifically, turbopumps and regeneratively-cooled nozzles are being developed. The NASA has also assumed responsibility for liquid hydrogen supply. A flight demonstration program leading to a useful application will later be conducted under the management of the NASA with the AEC providing reactor support. Planning which includes a flight phase is quite important since it serves to establish meaningful performance objectives in terms of power level, power density, and acceptable operating temperatures early in the reactor program. 
Activities carried on at Los Alamos includes materials development, neutronics studies, reactor design, controls development, test operations planning, and research on advanced concepts. A major part of the over-aII effort is devoted to fuel element materials develooment. The number of candidate materials for the required temperature service is small, but they represent a class of materials about which relatively little is known. Work required covers everything from determination of phase diagrams to simulated hydrodynamic testing of uranium-loaded fuel elements. Such testing is done by flowing hydrogen through electrically heated fuel element samples at flow rate, velocity, pressure, and temperature conditions of reactor service. Facilities available can place several megawatts of electrical power on the Iine for this purpose. Data from these experiments, critical assemblies, and that obtained from coded computer runs are applied to the design of test reactors.

The Iimitations of reactor calculation techniques and the complex interplay of many variables which affect control and performance characteristics led to an early decision to fabricate and test an experimental reactor. Reactor test operation has become the largest single program activity. A basic complex of test facilities was constructed for such testing at the AEC's Nevada Test Site suitable for assembly, test, dissassembly, and limited post-mortem examination of such reactors. A description of these facilities has been adequately covered by others ${ }^{7}$ and will not be repeated here. A series of reactor 
experiments is now planned to sequentially attack all the known problems of nuclear rocket operation.

Before these reactors can be tested, cryogenic components for storage, delivery, metering and control of liquid hydrogen must be available. It may come as a surprise to some, but the leadtime on many such components is Ionger than that required for test reactors. The A ir Force demonstrated considerable foresight when they began the design and development of a liquid hydrogen pump for the Rover program in 1956. This pumo, an axial flow design, is the largest capacity liquid hydrogen pump known to exist today. Reminiscent of the early days of turbojet development, there are differences of opinion as to whether axial flow or centrifugal flow pumps are best suited to the nuclear rocket. You may recall, in the case of the turbojet, the demands for high performance and small size forced the centrifugal compressor out of competition. Consider that the volume flow rate of the oxygen pump which feeds a 150,000 Ib. thrust Atlas missile engine is 2600 gals/minute. An equivalent capacity hydrogen pump rould be adequate to cool a $400 \mathrm{MN}$ reactor in a nuclear rocket producing 20,000 Ibs. thrust. In view of the low density of hydrogen, it is clear that high thrust molear rocket engines will require extremely high capacity hydrogen pumps.

Engine thrust, reactor power, and hydrogen flow rate are intimately associated performance variables which require that flow rate be accurately known. This poses some difficult problems with regard to 
accurate temperature sensing and flow metering of hydrogen. The development of leak-tight valves poses unique problems in that such hardware is fabricated at room temperature and mist retain accurate clearance tolerances several hundred degrees below that temperature. Unlike Iiquid oxygen lines and valves which can be insulated with solid material, Iiquid hydrogen components must be vacuum-jacketed to reduce heat leak to acceptable levels. Among the facilities being provided to support reactor experiments in Nevada is a cryogenic test facility to develop and test Iiquid hydrogen combonents orior to their assembly into experimental reactor installations.

The foregoing discussion mentions only some of the activities and problems associated with Project Rover. Others are covered elsewhere in this text. Perhaps no single development effort heretofore has been required to extend the state of knowledge in such a variety of low temperature, high temperature, nuclear, and mechanical engineering areas.

\section{$\underline{K I W I-A}$}

The first of the planned series of reactor experiments in Project Rover was completed last summer. In a humorous vein, this reactor was named Kiwi-A after the flightless Australian bird. Since the reactor reighed more than the thrust it could produce, the name was appropriate, although neither thrust nor weight were quantities of interest for its design. The test was conducted in an area known as Jackass Flats, not many miles from the better known Frenchman Flat, of the AEC Nevada Test 
Site at Mercury, Nevada. Kiwi-A is shown in Figure 3 mounted on its test car which transported it by rail from the assembly building to the test cell.

In order to insure maximum internal simplicity and avoid development of regeneratively-cooled test hardware at this time, separate watercooled loops were provided for the pressure shell and nozzle. The nozzle area ratio was made small to minimize cooling water requirements. Some heavy water moderation was used to minimize both the fuel volume and propellant flow rate. I These features also permitted certain program economies. The large amount of external piping would obviously not be present on an actual engine. The box-like structure below the reactor housed the control rod drive mechanism and the terminal board for several hundred instmumentation connections. Instrumentation lines and cooling services were connected to the test cell through a shielded umbilical plug which mated to a female port in the test cell wall and through quickdisconnect fittings. The instrumentation and control signals were carried by buried cable to the control building approximately two miles distant. Closed circuit television and remote controlled motion picture services were provided between the control building and test cell area.

Kiwi-A was tested in the nozzle-up position. This test configuration provides both a simple and economical installation at the test cell. As a point of interest, there do not appear to be compelling reasons for testing a nuclear rocket engine in the down-firing position. Chemical rockets are 
normally down-fired as a safety precuation to prevent fuel-oxidizer mixtures from exploding either on ignition fajlure or from residual afterheat on shutdown with propellant leakage. For the Kiwi-A test hydrogen gas flow was initiated prior to power mum and the hydrogen Iighted off by a butane torch which passed over the nozzle on a swivel from the test cell face. No reactor shielding was provided nor was any attempt made to contain the reactor or fission products in the exhaust gas. In contrast to facility design philosophy as applied to power reactor operation, rocket reactor testing recognizes a potential test hazard and testing is accomplished at a remote site where the extent of any hazard may be carefully controlled and evaluated. The two mile distance between test cell and control building in this case was based upon permitting direct observation in the open of a test of a reactor designed for moch higher power levels than Kiwi-A, with the prevailing wind away from the control area. The control building and its occupants are adequately protected in the event of a wind reversal during a power man. It is interesting to note that safety distances for adequate control room protection during nuclear rocket operation are not far different from those required for chemical rocket testing.

The primary objective of the Kiwi-A test was to operate the reactor at high power at a predetemined temperature level and a duration representative of an operational cycle. Several preliminary experiments were conducted to check out coolant subsystems, instrumentation, controls, and communications. With regard to the reactor, a critical 
experiment and one run at low power with all subsystems operating was made prior to the high power test. The latter test was successful on the first attempt; a significant achievement in any type of power plant initial operation.

During operation the radiation levels close to the reactor were, of course, extremely high. In addition, fission products from recoil and diffusion were carried out the nozzle to the atmosphere. Radiation measurements were an imoortant part of the test operation and an elaborate array of instrumentation for such measurements was provided. There were 60 instrumented stations covering a $115^{\circ}$ downwind segment, located on arcs from 2,000 feet to 2.5 miles from the reactor. These stations were equipped with film badges, particulate air samplers and fallout trays. Radsafe observations were also made at more remote locations of the test site up to 20 miles away. Air sampling and stationary gamma monitors were located around the periphery of the test site. Solid propellant JATO units with smoky exhaust were fired at Intervals from the test cell roof to mark the hot rising exhaust from the reactor for sampling aircraft.

Maximm fallout of fission products occurred less than a mile from the reactor. The radiation level was such that a man standing exposed at this location during the test would have received no more than a one-week occupational dose from all fallout effects. Off-site measurements were negative except for a single location where a trace, slightly 
above background, was detected. Recovery teams removed foil samples placed against the sides of the reactor with in 24 hours. The reactor was removed from the test cell and transported to a shielded disassembly bay approximately two weeks after the test. The test cell area was cool enough for maintenance operations at this time.

The reactor was disassembled using remote manipulator equipment. An elaborate and well planned post-mortem examination and diagnostic analysis of internal comoonents was conducted which yielded valuable information for later reactor designs. A new series of reactor experiments will be conducted during the coming summer. 


\section{SPACE VEHICIE PERFORMANCE}

The foregoing discussion has been confined to a description of the nuclear rocket and a comparison of its performance with that of its chemical counterpart. While such considerations are interesting and instructive, they do not provide sufficient guidance for an engine development program. One must decide where and how the engine is to be used before power requirements and performance goals can be adequately specified.

\section{Generalized Performance Considerations}

The background to formulation of preliminary engine specifications can be obtained by comparing the over-all performance of space vehicles powered by nuclear or chemical stages. Simple analytical methods are available which are well suited for surveying vehicle performance over a wide spectrum of missions. In the discussion to follow, payload fraction, or ratio of payload weight to vehicle gross weight, is used as the primary measure of over-all vehicle performance. Analogous to the artillery problem where muzle velocity determines projectile range, space mission capability is determined by a single parameter known as characteristic velocity. This velocity is defined as the actual vehicle velocity at thrust termination plus an allowance for drag and gravity losses during powered flight. Other important considerations are engine and airframe weight, specific impulse, and the number of stages employed. In the case of chemical stages, specific 
impulse, specific engine weight and specific airframe weight all depend. on the propellant combination used, and all can be considered constant over a wide range of engine thrust and vehicle weight. The payload fraction that can be expected for any characteristic velocity is illustrated in Figure 4 for kerosene and oxygen, the propellants widely used today in ballistic missiles and space vehicles. As illustrated, the payload fraction vanishes for a single stage vehicle at a characteristic velocity less than 30,000 feet/second. Hence, for all missions requiring a greater velocity, the vehicle designer must resort to staging. There is a practical limit beyond which small payload gains do not justify additional stages, and an ultimate limit characterized by an infinite number of stages. Payload fraction can only be improved and mission limits extended by higher specific impulse. Vehicles using different propellant combinations can be conveniently compared by assuming the infinite staging arrangement for each. Such a comparison is shown in Figure 5 for the kerosene-oxygen and hydrogen-oxygen chemical systems. In this case, the striking advantage of the hydrogen-oxygen vehicle is almost entirely due to its higher specific impulse, 415 as compared to 310 for the kerosene-oxygen vehicle. The resultant payload advantage, or ratio of payload fractions, depends strongly on mission difficulty. Figure 5 shows, for example, that a hydrogen-oxygen ICBM of equal gross weight could deliver twice the payload of current missiles while the payload fraction for the more difficult Iunar mission would be more than trippled. It is for this reason that the NASA has recently 
decided to develop hydrogen-oxygen engines for use in space vehicles.

With one exception, the same generalized performance analysis can also be applied to vehicles using one or more molear stages. Specific engine weight is not a constant due to the minimum engine weight limitation posed by reactor criticality requirements, and payload fraction is influenced by muclear stage weight as well as specific impulse. Assuming a specific impulse of 800 for thermal reactor nuclear engines and a specific impulse of 850 for fast reactor nuclear engines, the payload fraction has been calculated for several vehicle weights. A comparison with hydrogen-oxygen vehicles of the same gross weights is obtained by forming the ratio of the respective payload fractions. This ratio is plotted against characteristic velocity in Figure 6. In this figure, the nuclear system is superior for any ordinate value greater than unity. Although these curves are calculated on the basis of an infinite number of stages for both muclear and chemical systems, they provide a good approximation for comparison of single stages, a series of consecutive stages, or complete vehicles. Several interesting facts emerge which place the application of nuclear rockets in proper perspective.

a. The payload advantage of nuclear systems increases rapidly as greater velocity increments are required.

b. As one might expect, the payload advantage of nuclear systems increases as stage weight increases. This is due to the fact that minimum critical weight becomes a smaller fraction of total engine weight in large vehicles. 
c. Fast reactors look more attractive than thermal reactors in applications where total stage weight is low because of their lower minimum weight at low power levels. This suggests their use in upper stages only. Conversely, at stage weights greater than 200,000 Ibs., the thermal reactor engine gains the advantage.

\section{Early Applications}

Plans for development of two large space vehicles of increasing payload capability for successive periods of use have been announced by the NASA. A general description of the first of these vehicles, the Saturn, was recentIy given to the House Committee on Science and Astronautics. 8 A proposed configuration for the second vehicle, called Nova, is completely described in an article by Rosen and Schwenk 9 of the NASA. The chemical booster rockets of very large thrust for these vehicles require long leadtime, and these developments are already underway using the kerosene-oxygen propellant combination. The Saturn booster consists of a cluster of eight 186,000 1b. thrust engines to provide 1,500,000 Ibs. thrust, and the proposed Nova booster consists of $\operatorname{six} 1,500,000 \mathrm{lb}$. thrust single-chamber engines to provide 9,000,000 Ibs. thrust. A series of hydrogen-oxygen engines will be developed for use in upper stages of Saturn. 8 The payload capabilities of these vehicles for a soft landing on the moon, as an example, are about 9,000 Ibs. for Saturn and 36,000 Ibs. for Nova. 
The current economic climate indicates that the initiation of new vehicles and improved stage developments will be carefully considered to insure that the potential payload gains justify the cost. It is believed, therefore, that early application of nuclear rockets must be judged in terms of the performance improvement possible when nuclear stages are integrated into vehicles of the type now planned. For such early applications it is assumed that nuclear rockets will use thermal reactors. As a practical means of estimating the power levels that might be required and what payload advantages would accrue, let us consider replacing certain stages of the Saturn vehicle with nuclear stages.

In the analysis to follow, resultant payload fractions and reactor powers required are calculated for each individual case considered based on methods more exact 4 than those used to obtain the generalized results of Figure 6. The characteristics of a Saturn vehicle as it might be configured for a soft lunar landing mission are estimated in Table $I^{8}$

Table I

\begin{tabular}{lrrrc}
\hline Stage & $\begin{array}{c}\text { Stage } \\
\text { Weight } \\
(\text { Ibs })\end{array}$ & $\begin{array}{c}\text { Cumulative } \\
\text { Weight } \\
(\text { Ibs })\end{array}$ & $\begin{array}{c}\text { Stage } \\
\text { Thrust } \\
\text { (Ibs) }\end{array}$ & $\begin{array}{c}\text { Characteristic } \\
\text { Velocity Increment } \\
\text { (ft/sec) }\end{array}$ \\
\hline Payload & 9,000 & 9,000 & & \\
5th & 11,000 & 20,000 & 30,000 & 9,000 \\
4th & 35,000 & 55,000 & 80,000 & 11,500 \\
3rd & 95,000 & 150,000 & 200,000 & 11,500 \\
2nd & 250,000 & 400,000 & 800,000 & 11,500 \\
Ist & 700,000 & $1,100,000$ & $1,500,000$ & 8,100 \\
\hline
\end{tabular}


Since the lighter weight upper stages require less reactor power, one should consider replacing upper stages first. The cumulative weight of the fifth stage; that is, fifth stage weight plus payload, is only 20,000 Ibs. This is too small to consider replacing with a nuclear stage as illustrated by Figure 6. The curmlative weight of the fourth stage at 55,000 Ibs appears to be a break-even point, and will not be considered for the same reason. A $20 \%$ payload gain would result from replacing the third stage if it were designed to impart the same 11,500 feet/second velocity increment of the chemical stage. The velocity increment imparted by a stage is proportional to its specific impulse, so that much higher velocity increments can be provided by a single muclear stage. In this case, the maximum advantage is obtained by replacing all three upper chemical stages by one nuclear stage. Two important advantages are gained; the payload is doubled and the vehicle has been greatly simplified. The characteristics of the Saturn would now be as shown in Table II.

\section{Table II}

\begin{tabular}{|c|c|c|c|c|}
\hline Stage & $\begin{array}{l}\text { Stage } \\
\text { Weight } \\
(1 \mathrm{bs}) \\
\end{array}$ & $\begin{array}{c}\text { Cumulative } \\
\text { Weight } \\
\text { (Ibs) }\end{array}$ & $\begin{array}{l}\text { Stage } \\
\text { Thrust } \\
\text { (Ibs) } \\
\end{array}$ & $\begin{array}{c}\text { Characteristic } \\
\nabla \text { elocity Increment } \\
(\mathrm{ft} / \mathrm{sec})\end{array}$ \\
\hline Payload & 18,000 & 18,000 & & \\
\hline $3 r d \%$ & 132,000 & 150,000 & 100,000 & 32,000 \\
\hline 2nd & 250,000 & 400,000 & 800,000 & 11,500 \\
\hline lst & 700,000 & $1,100,000$ & $1,500,000$ & 8,100 \\
\hline \multicolumn{5}{|c|}{ * nuclear stage } \\
\hline
\end{tabular}


When substituting stages in this manner, the nuclear stage weight must equal the combined weight of all stages replaced to avoid modification of lower stages. It is not always advantageous to use a nuclear engine of the same thmust as that of the lower stage chemical engine replaced. By using an engine of lower thrust, engine weight is less, but higher gravity losses are incurred. Since the upper three stages of Saturn operate under conditions where gravity losses are small, the payload fraction is relatively insensitive to thrust or power level. This analys is indicates any reactor power level in the 1500 to 2500 megawatt range would be satisfactory, but a power of $2,000 \mathrm{MN}$ was optimum.

The next logical step would be to replace the second stage. This would require a reactor of $8,000 \mathrm{M}$, and the payload of the all-chemical vehicle is quadrupled, or increased to 36,000 Ibs. The same 2,000 M engine would be used to power a third stage, but the velocity increments of the second and third stages must be divided more equitably, and the third stage (propellant and tank) weight adjusted accordingly. This final Saturn vehicle is now configured as shown in Table III. Table III

\begin{tabular}{lcccc}
\hline Stage & $\begin{array}{c}\text { Stage } \\
\text { Weight } \\
(1 \mathrm{bs})\end{array}$ & $\begin{array}{c}\text { Cumulative } \\
\text { We ight } \\
\text { (1bs) }\end{array}$ & $\begin{array}{c}\text { Stage } \\
\text { Thrust } \\
\text { (lbs) }\end{array}$ & $\begin{array}{c}\text { Characteristic } \\
\text { Velocity Increment } \\
\text { (ft/sec) }\end{array}$ \\
\hline Payload & 36,000 & 36,000 & & 20,500 \\
3 rd* & 84,000 & 120,000 & 100,000 & 23,000 \\
2 nd* & 280,000 & 400,000 & 400,000 & 8,100 \\
Ist & 700,000 & $1,100,000$ & $1,500,000$ & \\
$*$ nuclear stages & & & \\
\hline
\end{tabular}


We now have a three-stage Saturn vehicle having a payload capability four times that of its five-stage chemical configuration, and having the same payload capability of a four-stage Nove, its proposed successor. In the opinion of the authors the Satum vehicle configuration of Table III could be achieved for operational use within the next 15 years.

The relative economies of utilizing nuclear rocket engines is difficult to evaluate without prior operational experience with large and expensive space vehicles. A few estimates of vehicle and engine costs may be helpful in this regard. An average cost of $\$ 150$ per pound of dry weight for the first 100 vehicles procured is considered a reasonable estimate. On this basis, the all-chemical Saturn and Nova vehicles, as examples, would cost $\$ 4,000,000$ and $14,000,000$. respectively, exclusive of payload and launching costs. The chemicalnuclear Saturn would cost $\$ 24,000,000$, including an estimated cost of p10,000,000 for the two reactors. Hence, it would appear that a saving of about $\$ 24,000,000$ in vehicle cost would accrue for those missions where the improved Saturn can be used in place of the proposed Nova. An alternate approach would be to compare the vehicle costs per pound of payload delivered. Using the lunar landing payload as basis of comparison, the cost per pound of payload delivered would be $\$ 1600 / 1 b$. for the all-chemical Saturn, $\$ 1400 / 1 b$. for the Nova, and $\$ 700 / 1 b$. for the chemical-nuclear Saturn. An important additional consideration in 
estimating relative costs is the greater probability of successful delivery of any payload using a three-stage vehicle over a four or five-stage vehicle. The development costs for both the large chemical Nova stages and the nuclear stages for Saturn will be high and certainly of the same order of magnitude. While the foregoing estimates are not the result of detailed analysis nor are they all-inclusive, an economic advantage for using nuclear rockets is definitely indicated.

\section{CONCLUSIONS}

It is concluded that nuclear rockets can provide substantial performance, reliability, and economic advantages for the accomplishment of difficult space missions. The practical and inherent limitations of chemical rockets have been illustrated. Nuclear rocket engines based on relatively simple and well understood reactor concepts can greatly contribute to our over-all space posture within the next 15 years if timely decisions to proceed with their development are made. 


\section{REFERENCES}

1. Schreiber, R. E., "Nuclear Rocket Propulsion," Air University Quarterly Review, Vol. XI, Nos. 3 and 4, Fall and Winter, 1959.

2. Rom, F. E., "Advanced Reactor Concepts for Nuclear Propulsion," Astronautics, October, 1959.

3. Clapper, R. B. and Corbin, A., "Propulsion Sub-System Areas Requiring Definition and Development in Preparation for Operational Nuclear Rockets," a paper presented at the annual meeting of the SAR, January $11-15,1960$.

4. Schmidt, H. R. and Decker, R. S., "Factors Which Will Influence Early Application of Nuclear Rockets," Transactions of the IRE Professional Group on Muclear Science, currently under publication.

5. Durham, F. P., "Solid Core Nuclear-Rocket Design," Astronautics, October, 1959.

6. Helgeson, B. P., "Nuclear Rocket Engine Control Problems in an Upper Stage Inter-Planetary Vehicle," a paper presented at the 6 th National Annual Meeting of the American Astronautical Society, January 18-21, 1960 。

7. Graves, G. A., "Radiation Problems in the Rover Program," a paper presented at the Semi-Annual Meeting of the American Rocket Society, June 8-11, 1959.

8. Schreiber, R. E., "Los Alamos' Project Rover," Mucleonics, Vol. 16, No. 7 , July, 1958 .

9. Aviation Week, Space Technology Section, Vol. 72, No.6, February 8, 1960.

10. Rosen, M. W. and Schwenk, F. C., "Nova-A Manned Lunar Rocket," Astronautics, September, 1959. 


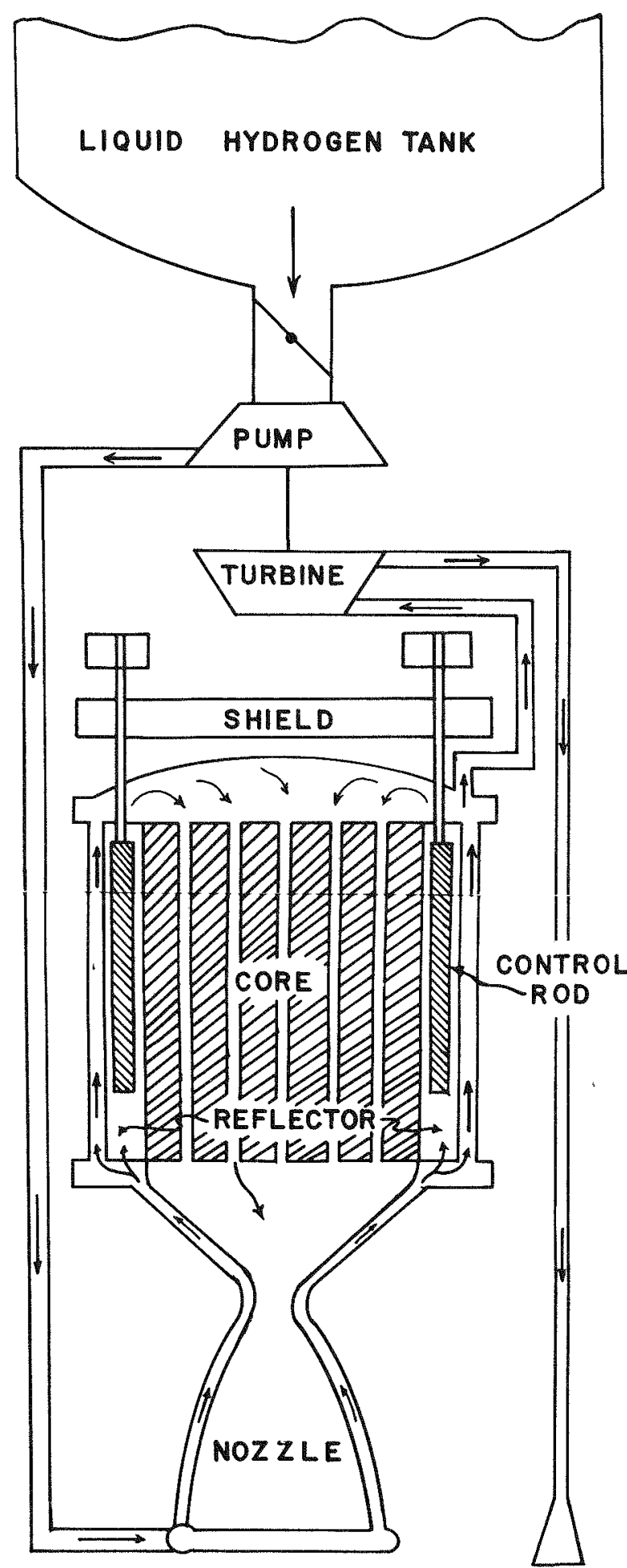

NUCLEAR ROCKET SCHEMATIC

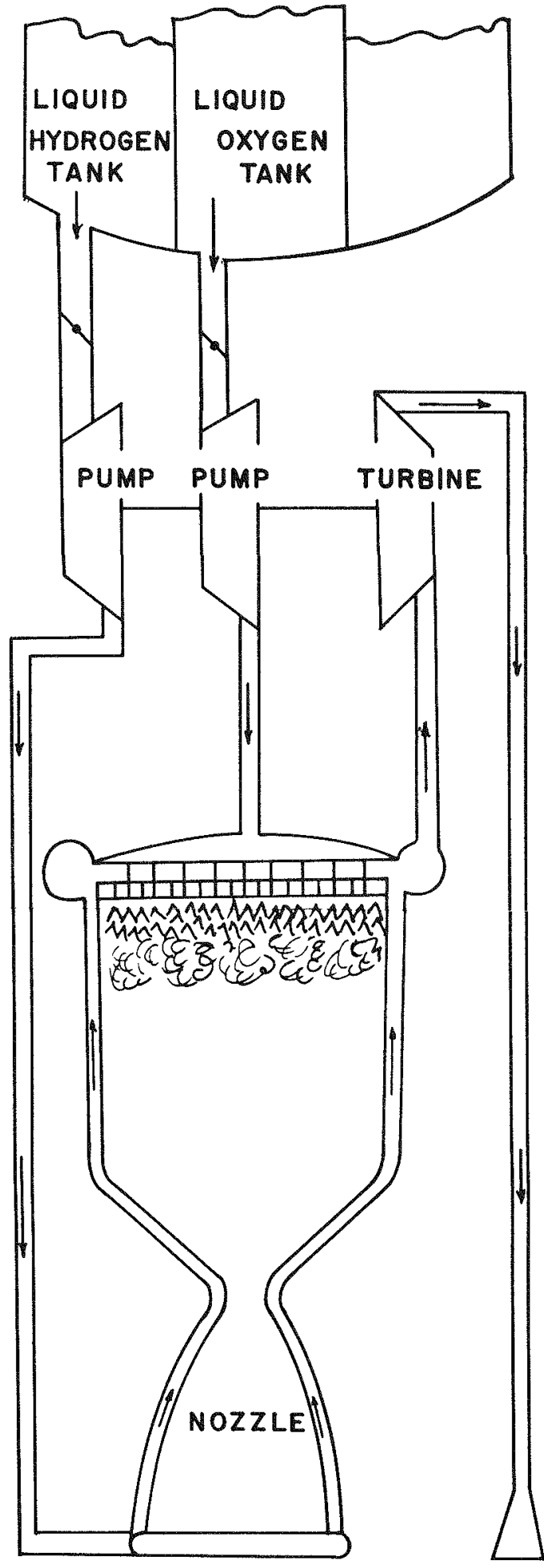

CHEMICAL ROCKET SCHEMATIC

Figure 1

Schematics of nuclear and chemical rocket engines. 


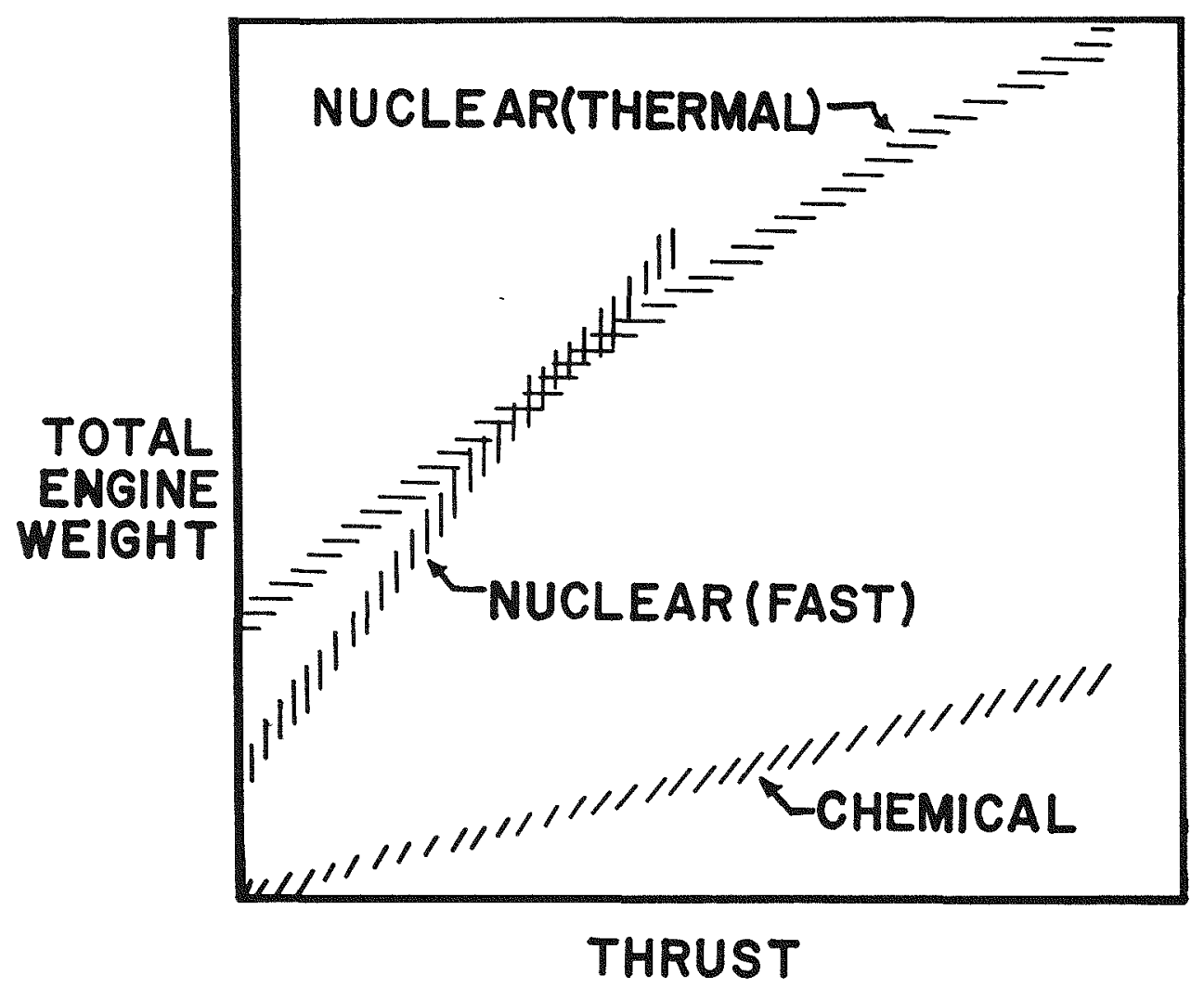

Figure 2

Weight of nuclear rocket engines using fast and thermal reactors compared with chemical rocket engines. 


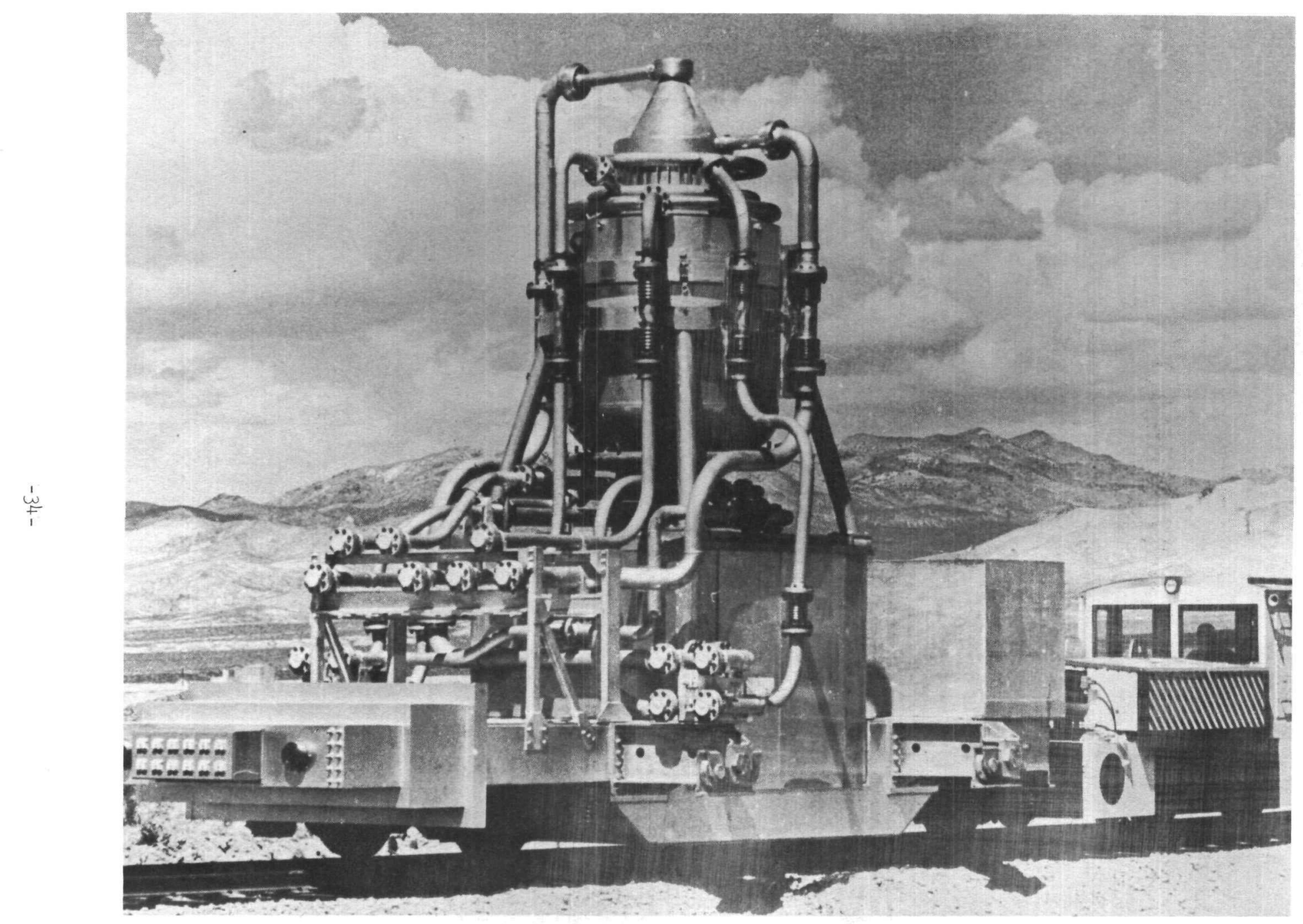

Figure 3

Yiwi-A, The first experimental reactor tested in the ?over Program. 


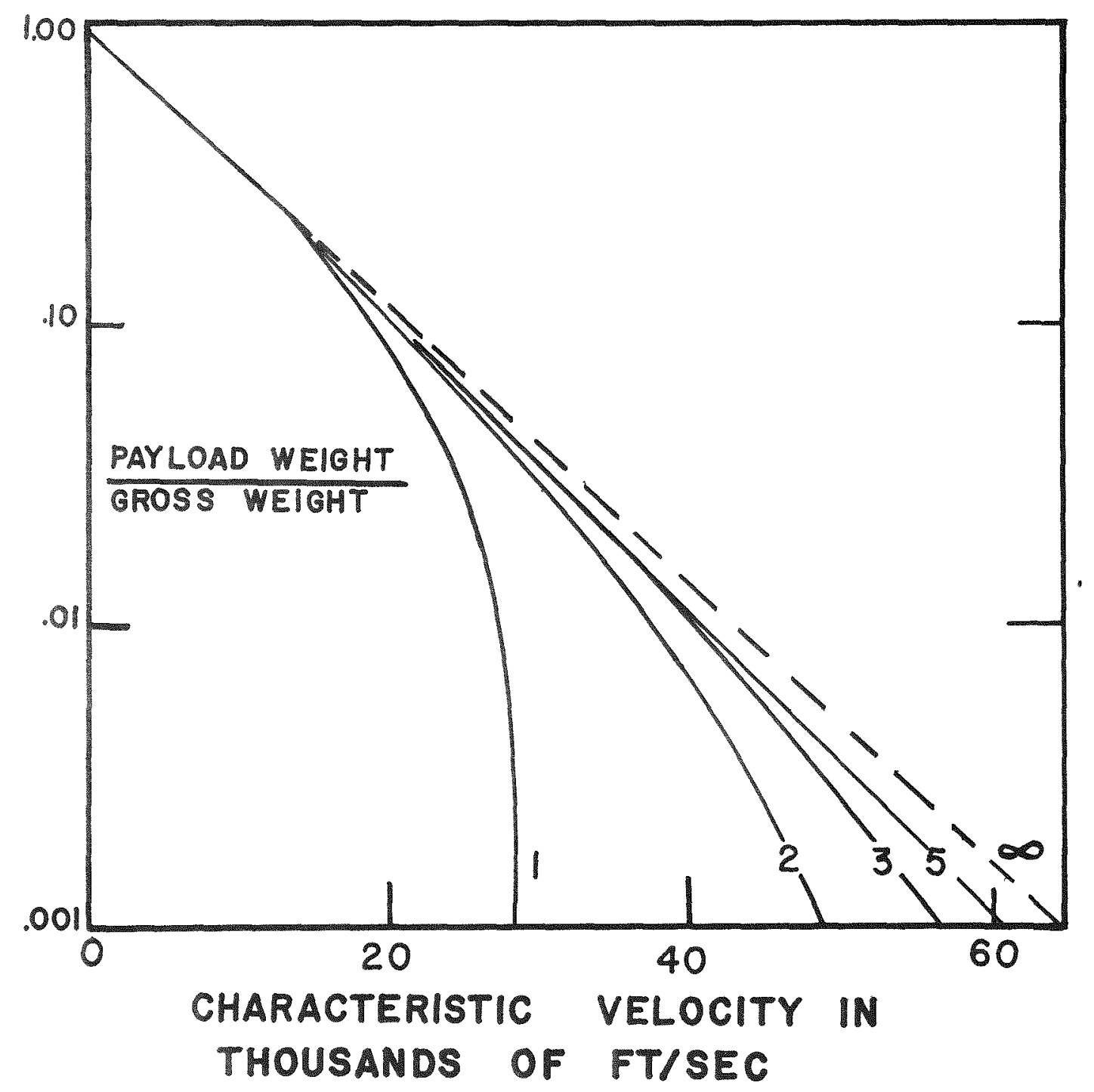

Figure 4

Payload fraction vs. characteristic velocity for single and multistage vehicles using kerosene-oxygen propellants. 


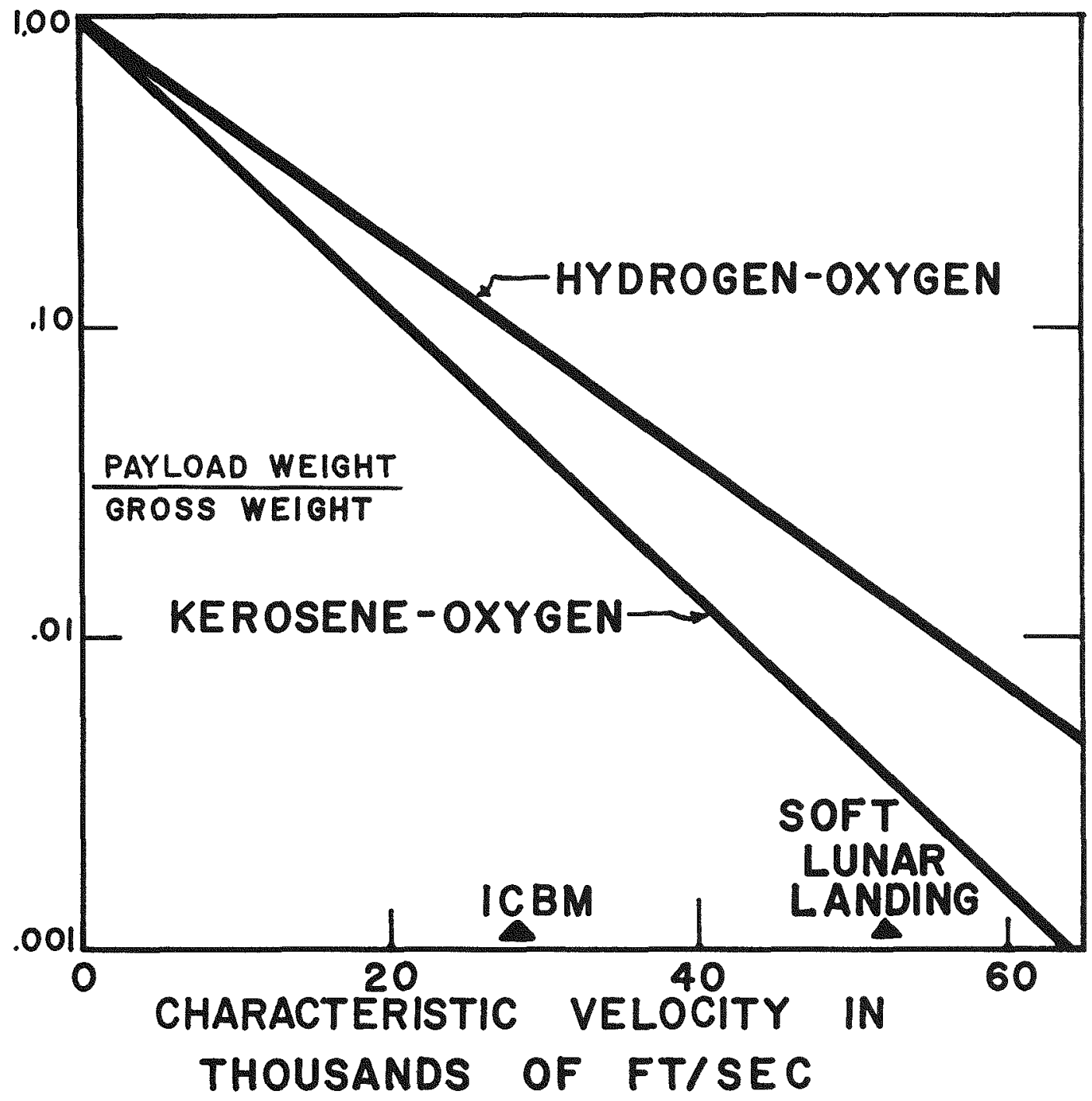

Figure 5

Compaxison of payload fraction for vehicles using hydrogen-oxygen and kerosene-oxygen propellants. 


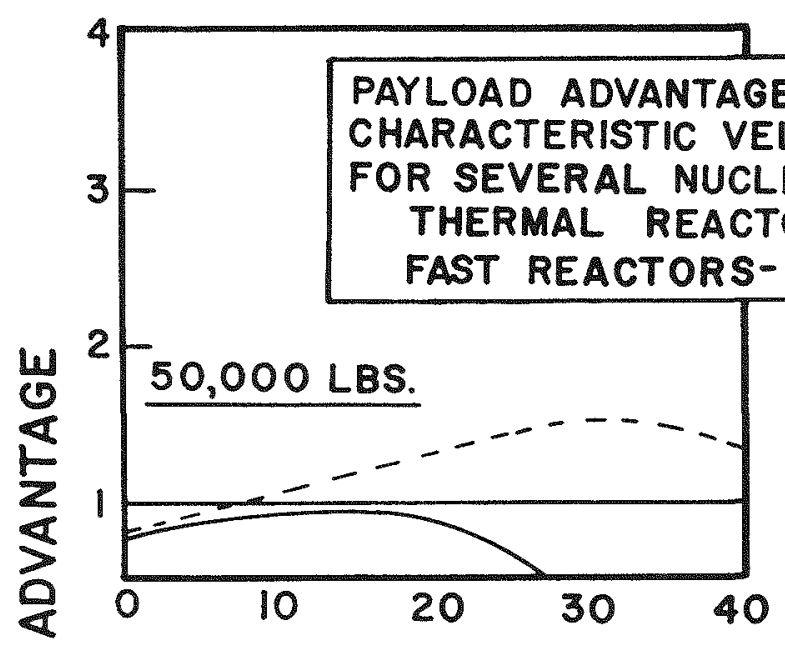

$4 \longdiv { }$

CHARACTERISTIC VELOCITY INCREMENT

OR SEVERAL NUCLEAR STAGE WEIGHTS THERMAL REACTORS

FAST REACTORS -.......
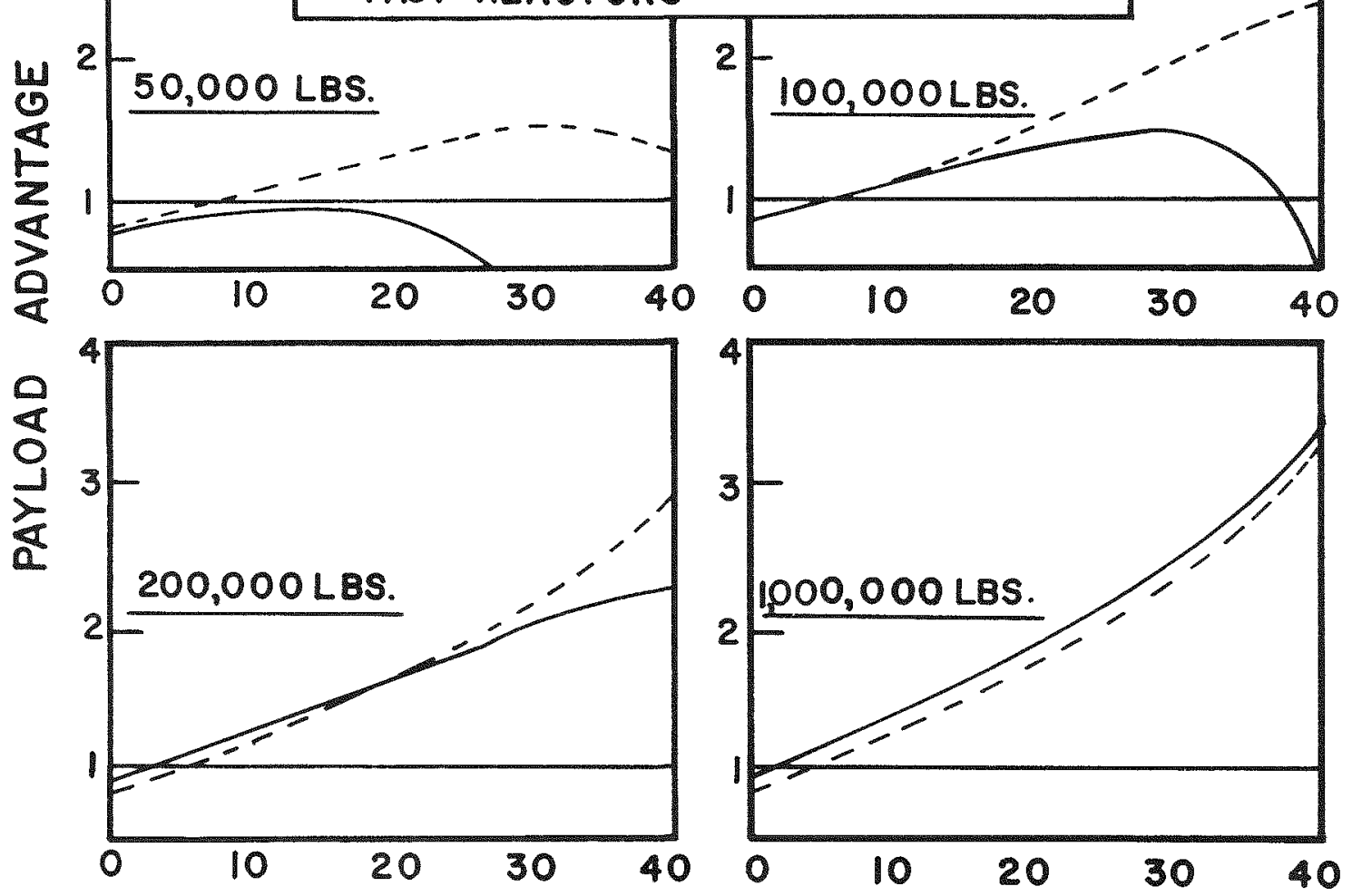

CHARACTERISTIC VELOCITY INCREMENT

THOUSANDS OF FT/SEC

Figure 6

Payload advantage of nuclear vehicles for several vehicle weights. 


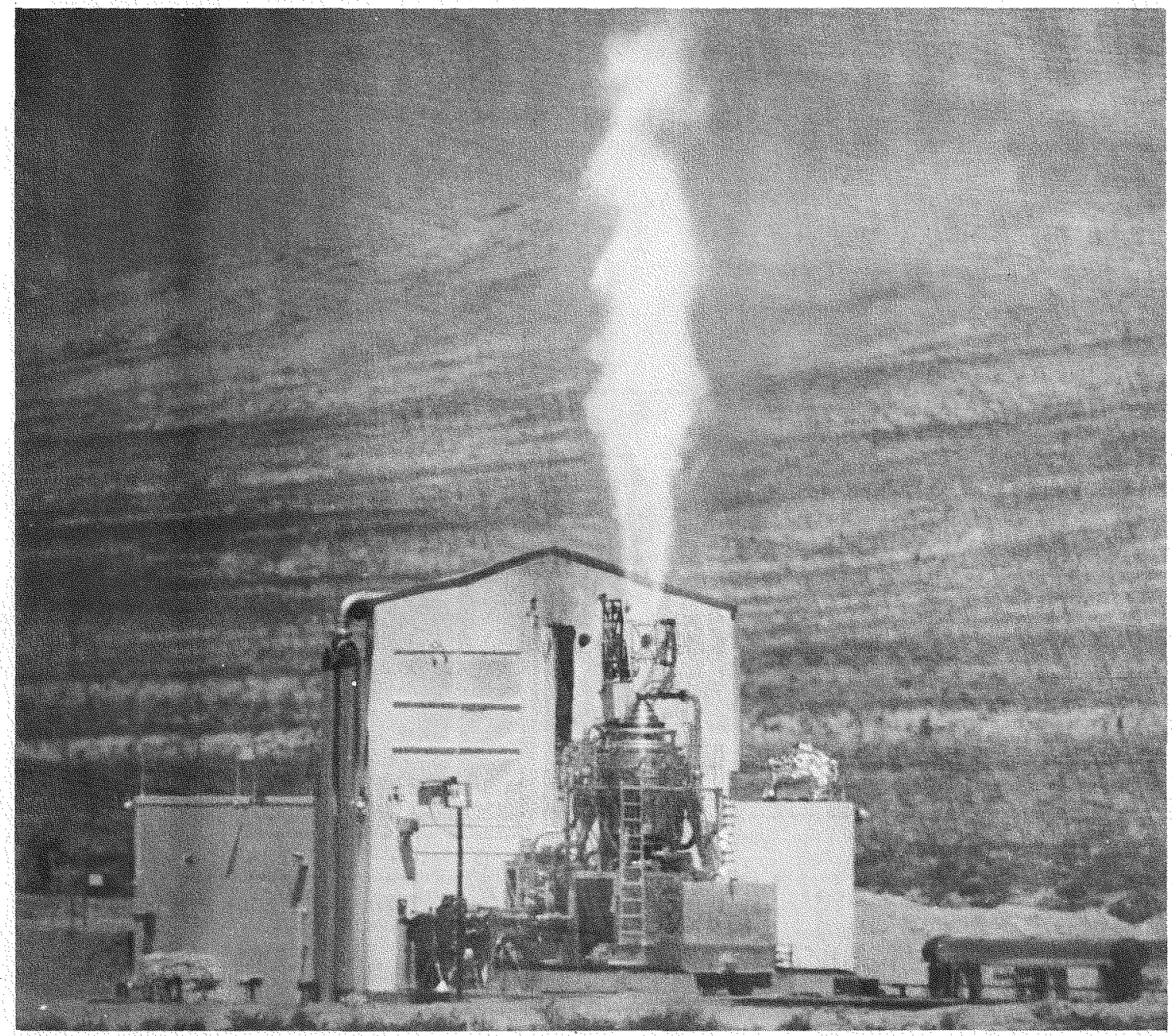

\section{Figure 7}

Kiwi-A in full-power operation on 1 July, 1959. This picture is enlarged from a frame of a movie camera located approximately 500 yards from the test cell. The hydrogen exhaust flame extends considerably beyond the luminous central column. Since it is transparent, it can be observed in the photograph only by the blurring details of the mountains in the background. 


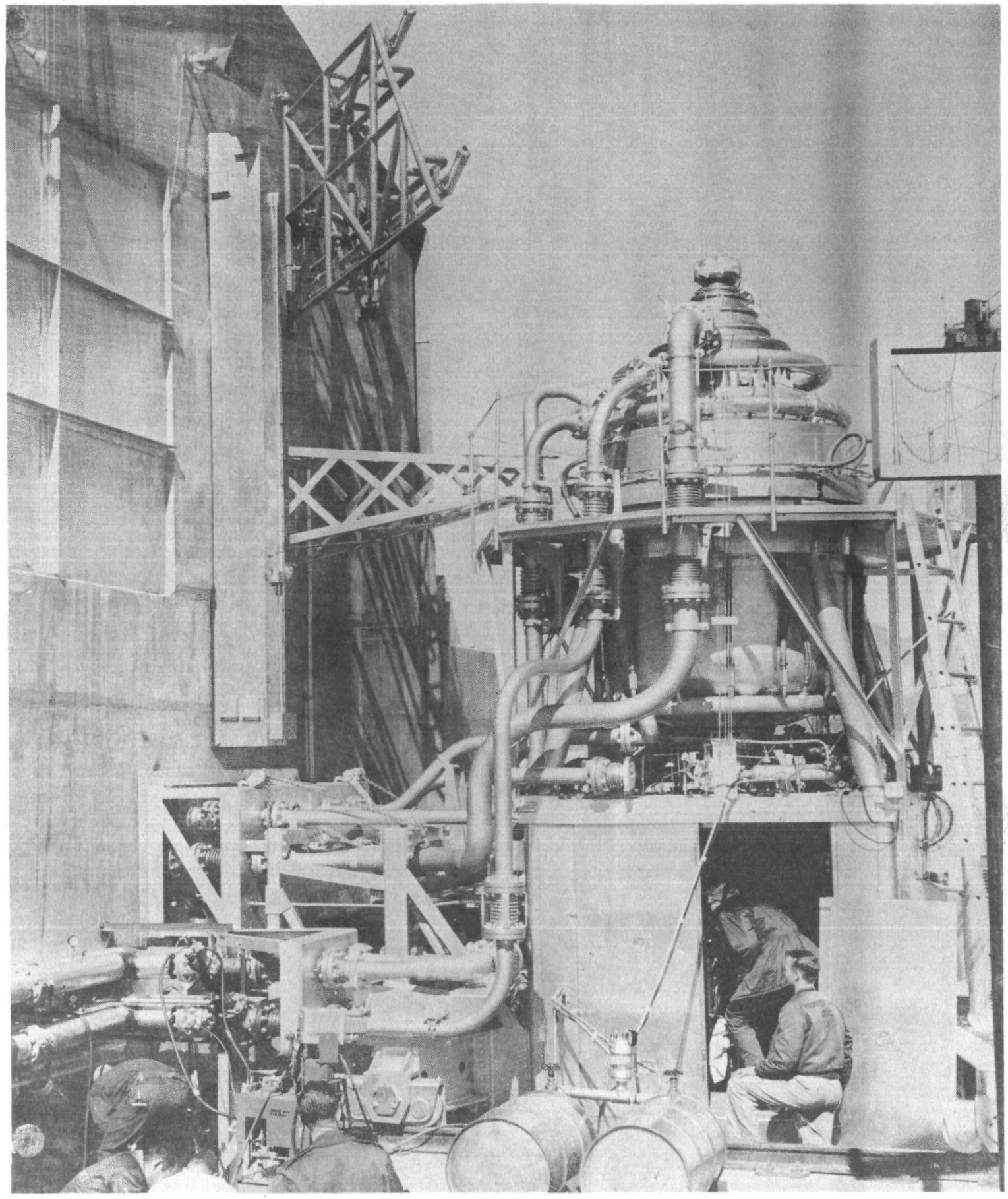

Figure 8

Kiwi-A, the first Rover experimental reactor, as it was coupled to the test cell prior to test. Following the test, it was remotely decoupled and transported by rail to the disassembly building on the special test car shown. 